\title{
- Complexo teníase humana - Cisticercose bovina e suína II - Cisticercose bovina e suína
}

\section{- Human taeniasis - cattle and swine cysticercosis complex II - Cattle and swine cysticercosis}

José de Angelis Côrtes - CRMV-SP n ${ }^{0} 0007$

Médico Veterinário, Professor Titular de Zoonoses. (Aposentado) - FMVZ - USP.

\section{RESUMO}

A cisticercose tem sido considerada uma das mais importantes zoonoses conhecidas, não apenas pelos agravos à saúde animal e conseqüentes implicações econômicas, mas também pela gravidade da doença na população humana. Seu agente causal é representado pela forma larvar da Taenia solium e da Taenia saginata. O presente artigo focaliza a história natural e conseqüente prevenção da doença, tendo como base a relação interativa existente entre as formas adulta e larvar dos referidos parasitas e seus correspondentes hospedeiros, cuja apreciação impõe uma abordagem dicotômica e complementar dos mecanismos de transmissão do complexo teníase - cisticercose, a saber: sentido animal x homem (teníase), apresentado no artigo anterior, e sentido homem $\mathrm{x}$ animal (cisticercose), indissociáveis, no contexto holístico da abordagem, enfatizando: a) o papel dos portadores de cisticercose na transmissão da teníase humana; b) o significado do curso silencioso da doença e da inespecificidade das manifestações clínicas; c) a importância de um sistema de vigilância epidemiológica, objetivando a identificação dos grupos de risco e a correspondente intervenção preventiva; d) as ações preventivas diretas, que estariam apoiadas: 1) no diagnóstico e tratamento dos portadores humanos da teníase, subsidiado operacionalmente pela Inspeção Veterinária, detectando os casos de cisticercose, associando-os com os rebanhos de origem dos animais afetados e notificando ao sistema de saúde humana; 2) no saneamento ambiental, particularmente orientado para o adequado destino e tratamento dos excretas humanos; 3) na proteção inespecífica dos suscetíveis, com práticas de manejo sanitário, nas populações animais e de higiene pessoal e alimentar para a população humana; 4) na participação comunitária, orientada de forma segura e pontual acerca dos procedimentos individuais e conjunturais de prevenção.

Palavras-chave: complexo teníase-cisticercose, cisticercose animal, cisticercose humana, Cysticercus cellulosae, Cysticercus bovis. 


\section{Caracterização}

$\underline{\mathrm{N}}$ o presente artigo empregaremos o termo "cisticercose" para designar, indistintamente, o estado patológico resultante do parasitismo, de hospedeiros vertebrados, pela forma larvar da Taenia solium ou da Taenia saginata, e caracterizado por uma lesão vesicular, denominada cisticerco.

A cisticercose é conhecida desde os tempos préhistóricos. Já Aristóteles (384 - 322 a.C.), em sua obra "História Animalium" faz referência a uma doença, em suínos, caracterizada por formações císticas comparáveis a pedras de granizo. A associação desta patologia com agravos à saúde humana evidenciou-se através de registros esparsos como: a descoberta do Cysticercus racemosus na base do cérebro humano (Wirchow, 1860); a presença de sintomas psiquiátricos (Berlin, 1862); a ocorrência de epilepsia (Labrose, 1867) e de meningite crônica (Heller, 1874), em pacientes afetados por tais estruturas. Todos esses fatos contribuíram para o estabelecimento de uma nova doença conhecida como neurocisticercose e sua correspondente morbidade no homem (PATAK, 1989).

Sua caracterização pode ser configurada pela imagem peculiar da história natural de uma parasitose cujos agentes necessitam, para sua persistência na natureza, da participação de duas espécies hospedeiras, uma das quais é, necessariamente, a humana.

De fato, a Taenia solium e a Taenia saginata, na forma adulta, têm como hospedeiro natural e obrigatório o ser humano, desenvolvendo, no intestino delgado, um processo conhecido como teníase humana; e, na correspondente forma larvar, utilizam-se do suíno e do bovino, respectivamente, como hospedeiros preferenciais, nos quais acarretam agravos característicos definidos como cisticercose (EUZEBY, 1966; PAWLOVSKY e SCHULTZ, 1972; ABDUSSALAM, 1974; CÔRTES, 1984; ALUJA et al.1987; PATAK, 1989; REY, 1991; ACHA e SZYFRES, 1996; OIE, 1996; TAKAYANAGUI, 1998).

\section{Distribuição geográfica}

Doença cosmopolita, encontrada, ao lado da teníase humana, em quase todas as partes do mundo. Sua ocorrência, contudo, varia de um lugar para outro em razão de numerosos fatores entre os quais figuram, com destaque, o sócio-econômico e a natureza das relações promíscuas ou higiênicas estabelecidas entre o ser humano e os demais hospedeiros dos cisticercos ora considerados (EUZEBY, 1966; ABDUSSALAM, 1974; BES-
SONOV, 1974; ALUJA et al., 1987; PATAK, 1989; VAZ et al., 1990; REY, 1991; EHNERT et al., 1992; LETTALU et al., 1992; SARTI et al., 1992; WCWGP, 1993; SCHANTZ et al., 1994; MOORE et al., 1995; VILLA, 1995; ACHA e SZYFRES, 1996).

No homem a ocorrência da cisticercose (Cysticercus cellulosae) apresenta distribuição espacial similar à da cisticercose suína, paralela, portanto, à prevalência da Taenia solium (ABDUSSALAM, 1974; ACHA e SZYFRES, 1996; EUZEBY, 1966). Contudo, em algumas regiões, tal associação não tem sido constatada, fazendo supor que outros cisticercos distintos do da $T$. solium possam intervir na cisticercose humana (ABDUSSALAM, 1974; ACHA e SZYFRES, 1996).

\section{Importância social e econômica}

Figuram entre as principais consequiências sociais: o agravo direto acarretado à saúde humana, particularmente a neurocisticercose, e o papel que os animais portadores de cisticercose representam, como fontes de infecção, para a teníase humana. Por seu turno, o aspecto econômico inclui perdas diretas e indiretas decorrentes da doença nos animais, entre as quais: o elevado número de cistos na carcaça, muito freqüente na cisticercose suína, tornando-a imprópria para o consumo; a condenação total das carcaças altamente parasitadas; o tratamento, pelo calor, frio ou salga, das carcaças que apresentem baixo grau de parasitismo, onerando gravemente seu custo de produção e induzindo a certo grau de desvalorização, além das restrições comerciais (REY, 1991) e dos custos decorrentes dos agravos impostos à saúde humana.

\section{Etiologia}

A etiologia da cisticercose inclui a forma larvar de parasitas do gênero Taenia, neste caso representados pelas formas larvares da Taenia solium e Taenia saginata, também denominadas de Cysticercus cellulosae e Cysticercus bovis, respectivamente.

Um tipo adicional de tênia humana tem sido descrito como Taenia da Ásia ou Taenia de Taiwan, no Sudeste da Ásia. Sua forma adulta assemelha-se à Taenia saginata, todavia é armada com duas coroas de ganchos rudimentares e a forma larvar, o cisticerco, desenvolve-se principalmente no fígado de suínos, mas não em seres humanos (OIE, 1996). Cabe ainda mencionar que outras espécies do gênero Taenia podem acarretar, ocasionalmente, agravos à saúde 
Figura 1. Representação esquemática da Taenia saginata e da transmissão da cisticercose para a espécie bovina (Adaptada de OLSEN, O. W., 1979)
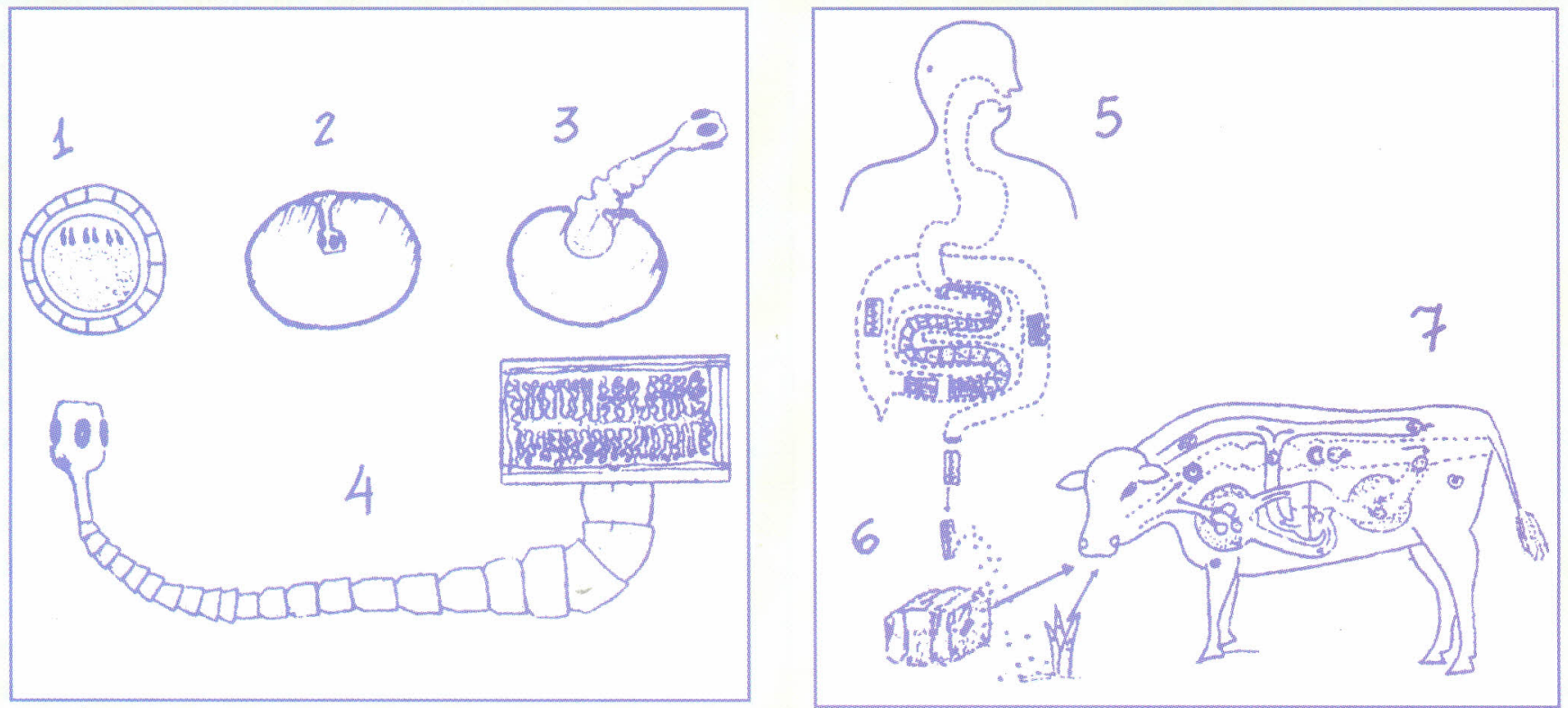

Fonte: CÔRTES, J.A. Comum.cient. Fac. Méd. vet. Zootec. Univ.S.Paulo. 8(2): 231-41, 1984.

1. Ovo da tênia com sua estrutura interna e envoltório externo; 2. Cisticerco invaginado; 3. Cisticerco desinvaginado; Taenia saginata (forma adulta); 4. Portador da tênia (Fonte de infecção); 5. Eliminação de proglotes e liberação dos ovos (Vias de eliminação); 6. Bovino ingerindo alimento contaminado com ovos da tênia e o fluxo da patogenia.

humana. É o caso da cenurose (Coenurus cerebralis), forma larvar da Taenia multiceps, do cão, que usualmente provoca cenurose cerebral, em ovinos, mas pode também afetar o cérebro humano; o cisticerco da Taenia ovis, que pode alojar-se na medula espinhal humana, registrada na Rússia, e os cisticercos da Taenia hydatigena e da Taenia taeniformis, encontrados parasitando o tecido hepático humano (REY, 1991; ACHA e SZYFRES, 1996). Em essência, este agente resulta da evolução de um embrião hexacanto, originalmente encerrado no interior de um ovo e protegido contra as adversidades do ambiente por um envoltório quitinoso, denominado de embrióforo. Tal proteção é responsável pela invulgar resistência dos ovos dessas tênias.

\section{Hospedeiros}

A associação hospedeiro-parasita assume, nesta parasitose, um caráter de relativa especificidade. De fato os hospedeiros preferenciais do Cysticercus cellulosae são o suíno e o javali, ainda que outros vertebrados como: o cão, o gato, o macaco e o próprio homem possam comportar-se como hospedeiros excepcionais; e os do Cysticercus bovis, os bovinos e zebuínos domésticos, embora possa também, este parasita, utilizar-se de outros hospedeiros como o búfalo, a girafa, a lhama, a ga- zela, o antílope, etc. (ABDUSSALAM, 1974; CÔRTES, 1984; ALUJA et al., 1987; PATAK, 1989; REY, 1991; OIE, 1996; ACHA e SZYFRES, 1996).

\section{Fontes de infecção}

Em que pese a existência de infecções experimentais em outras espécies (VESTER, 1974), a única fonte de infecção capaz de eliminar ovos viáveis da Taenia solium e/ou da Taenia saginata é representada pelo hospedeiro humano, portador da forma adulta destes parasitas (ABDUSSALAM, 1974; CÔRTES, 1984; ALUJA et al., 1987; PATAK, 1989; SCHENONE, 1989; REY, 1991; OIE, 1996; ACHA e SZYFRES, 1996) (Figuras 1 e 1A).

Tais portadores revelam-se fontes de infecção ricas, versáteis e duradouras, em razão de vários aspectos, entre os quais: a longevidade das tênias e a riqueza, em ovos, dos segmentos ovígeros, possibilitando a eliminação diária de uma enorme quantidade de ovos; a incapacidade dos anti-helmínticos usualmente utilizados de afetar a viabilidade dos ovos destas tênias; a ampla mobilidade dos portadores, favorecendo a dispersão dos ovos, uma vez que o próprio homem, deslocando-se livremente entre os rebanhos, incumbe-se de efetivá-la, especialmente no caso da $T a$ - 
CÔRTES, J. A. Complexo teníase humana - Cisticercose bovina e suína - II Cisticercose bovina e suína / Human taeniasis - cattle and swine cysticercosis complex II Cattle and swine cysticercosis. Rev. educ. contin. CRMV-SP / Continuous Education Journal CRMV-SP, São Paulo, volume 3, fascículo 2, p. 61 - 71, 2000.

Figura 1-A. Representação esquemática da Taenia solium e da transmissão da cisticercose para a espécie suína (Adaptada de OLSEN, O. W., 1979)

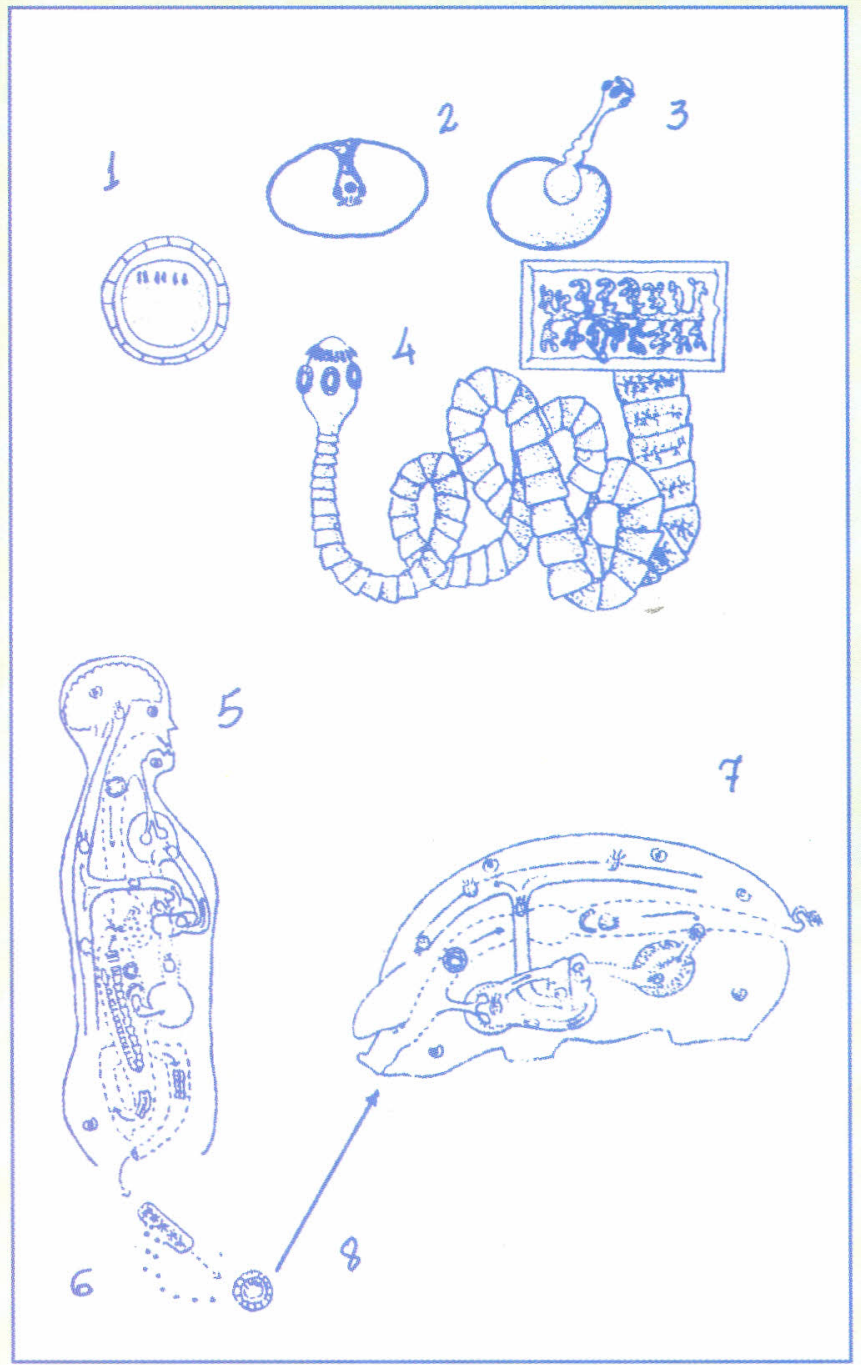

Fonte: CÔRTES, J.A. Comum. cient. Fac. Méd. vet. Zootec. Univ. S.Paulo, 8(2): 231-41, 1984

1. Ovo da tênia com sua estrutura interna e envoltório externo; 2. Cisticerco invaginado; 3.Cisticerco desinvaginado; 4. Taenia solium (forma adulta); 5. Portador da tênia (Fonte de infecção); 6. Eliminação de proglotes e liberação dos ovos (Vias de eliminação); 7. Suíno ingerindo alimento contaminado com ovos da tênia e o fluxo da patogenia.

enia saginata; o hábito de defecar diretamente no solo, praticado por trabalhadores, viajantes, turistas, romeiros, etc., ao longo das estradas, representa uma variável das mais relevantes, posto que se torna extremamente difícil uma atuação de saúde pública e/ou de saúde animal neste nível. Figuram, ainda, nos dias atuais, os fluxos migratórios de pessoas parasitadas, oriundas de áreas endêmicas de teníase humana, que se têm constituído num importante mecanismo de introdução da cisticercose em áreas livres da doença.

\section{Vias de eliminação}

As proglotes maduras das tênias são, usualmente, eliminadas do intestino humano com as fezes. No caso da Taenia saginata verifica-se uma particularidade significativa: os segmentos ovígeros desta tênia não são, usualmente, eliminados individualmente pelo verme. Na verdade eles destacam-se em grupos de 5 ou 6 anéis e abandonam ativamente o tubo digestivo do hospedeiro, forçando a passagem através do esfíncter anal, mesmo nos intervalos entre as defecações, de sorte que seu portador pode, involuntariamente, distribuí-los por onde passar: parques, jardins, estábulos, pastagens, etc.

\section{Vias de transmissão e fatores de risco}

A cisticercose, ora analisada, somente é adquirida pela ingestão, por hospedeiro adequado, de ovos viáveis de Taenia solium e/ou de Taenia saginata, de sorte que o mecanismo de maior importância em sua disseminação é representado pelo solo, água e alimentos contaminados com esses ovos (EUZEBY, 1966; ABDUSSALAM, 1974; ALUJA et al., 1987; CÔRTES, 1984; PATAK, 1989; SCHENONE, 1989; REY, 1991; ACHA e SZYFRES, 1996; OIE, 1996). Reside, pois, neste "elo" da cadeia de transmissão, o mais elevado nível de risco associado à infecção cisticercótica dos animais e do próprio homem, particularmente quando atentamos para as múltiplas possibilidades de contaminação da água e dos alimentos, entre as quais podem figurar:

\section{Contaminação direta do solo e alimentos}

O solo e os alimentos podem ser contaminados por fezes humanas eliminadas, diretamente nos campos de criação e de cultivo, por portadores de tênias. Isto ocorre, usualmente, em áreas pouco desenvolvidas onde existe uma estreita promiscuidade entre a população humana e seus animais. Sendo os porcos coprófagos voluntários o parasita encontra num ecossistema com tais características, as condições ideais para persistir na natureza. Este fato evidencia o importante papel desempenhado pelo homem no processo de disseminação da doença aos suínos, já que esta não prevalece em regiões em que as condições higiênicas são adequadas. Do mesmo modo, frutos e outros produtos vegetais expostos ao contato com o solo contaminado, quando ingeridos sem os devidos cuidados, podem veicular os ovos da tênia e transmitir a cisticercose ao ser humano. No caso particular da Taenia saginata, a permanente elimi- 
nação involuntária de proglotes pode levar, igualmente, à contaminação dos alimentos. Ordenhadores com mãos contaminadas com ovos desta tênia podem contaminar as tetas da vaca e, assim, transmitir a doença ao bezerro.

\section{Contaminação indireta dos alimentos}

O solo e os alimentos podem sofrer contaminação indireta quando excretas humanos (efluentes), inadequadamente tratados, são lançados nos mananciais de água ou utilizados como fertilizantes na adubação de pastagens ou na irrigação de culturas (EUZEBY ,1966; ABDUSSALAM, 1974; ALUJA et al., 1987; CÔRTES, 1984; PATAK, 1989; SCHENONE, 1989; REY, 1991; ACHA e SZYFRES, 1996; OIE, 1996); quando insetos e anelídeos (minhocas) que entraram em contato com fezes contaminadas transportam mecanicamente os ovos, contribuindo para sua disseminação; ou, pelo mesmo mecanismo, quando animais vertebrados envolvem-se nesse processo de transporte, especialmente algumas aves (gaivotas, gralhas, estorninhos, pardais, etc.) que, após alimentarem-se em esgotos lançados ao mar, ou em outros redutos de esgotos não tratados, vão contaminar as pastagens com ovos que passam pelo seu tubo digestivo sem sofrer qualquer alteração (ABDUSSALAM, 1974; ALUJA et al., 1987; CÔRTES, 1984; REY, 1991; ACHA e SZYFRES, 1996).

\section{Resistência dos ovos}

Epidemiologicamente, assume grande significado a resistência dos ovos destas tênias ao meio externo, particularmente quando envolvidos por uma fina película de água e em condições amenas de temperatura. Ovos de Taenia saginata podem sobreviver durante várias semanas ou meses em águas residuais, cursos d'água ou mesmo no pasto (ABDUSSALAM, 1974; ALUJA et al., 1987; REY, 1991). Do mesmo modo, os ovos destas tênias, embora sofrendo influência dos mecanismos biológicos de fermentação e putrefação, resistem à maioria dos processos de digestão usualmente adotados para a depuração de esgotos; são encontrados no líquido decantado dos tanques de sedimentação e resistem ao processo de fermentação, que se desenvolve no sistema de "lodos ativados", cujo produto denominado "lodo digerido seco" é utilizado com fertilizante (ABDUSSALAM, 1974; ALUJA et al., 1987; REY, 1991; ACHA e SZYFRES, 1996).

\section{Peculiaridades da transmissão da cisticercose ao homem}

A transmissão da cisticercose ao homem revestese de particular importância, em razão da sutileza dos mecanismos envolvidos (EUZEBY ,1966; ABDUSSALAM, 1974; ALUJA et al., 1987; CÔRTES, 1984; PATAK, 1989; SCHENONE, 1989; REY, 1991; ACHA e SZYFRES, 1996; OIE, 1996):

- Heteroinfecção: resultante da ingestão de alimentos contaminados com ovos de Taenia solium, eliminados com as fezes de outra pessoa;

- Auto-infecção exógena: conseqüente a um descuido de higiene pessoal, quando o indivíduo com teníase

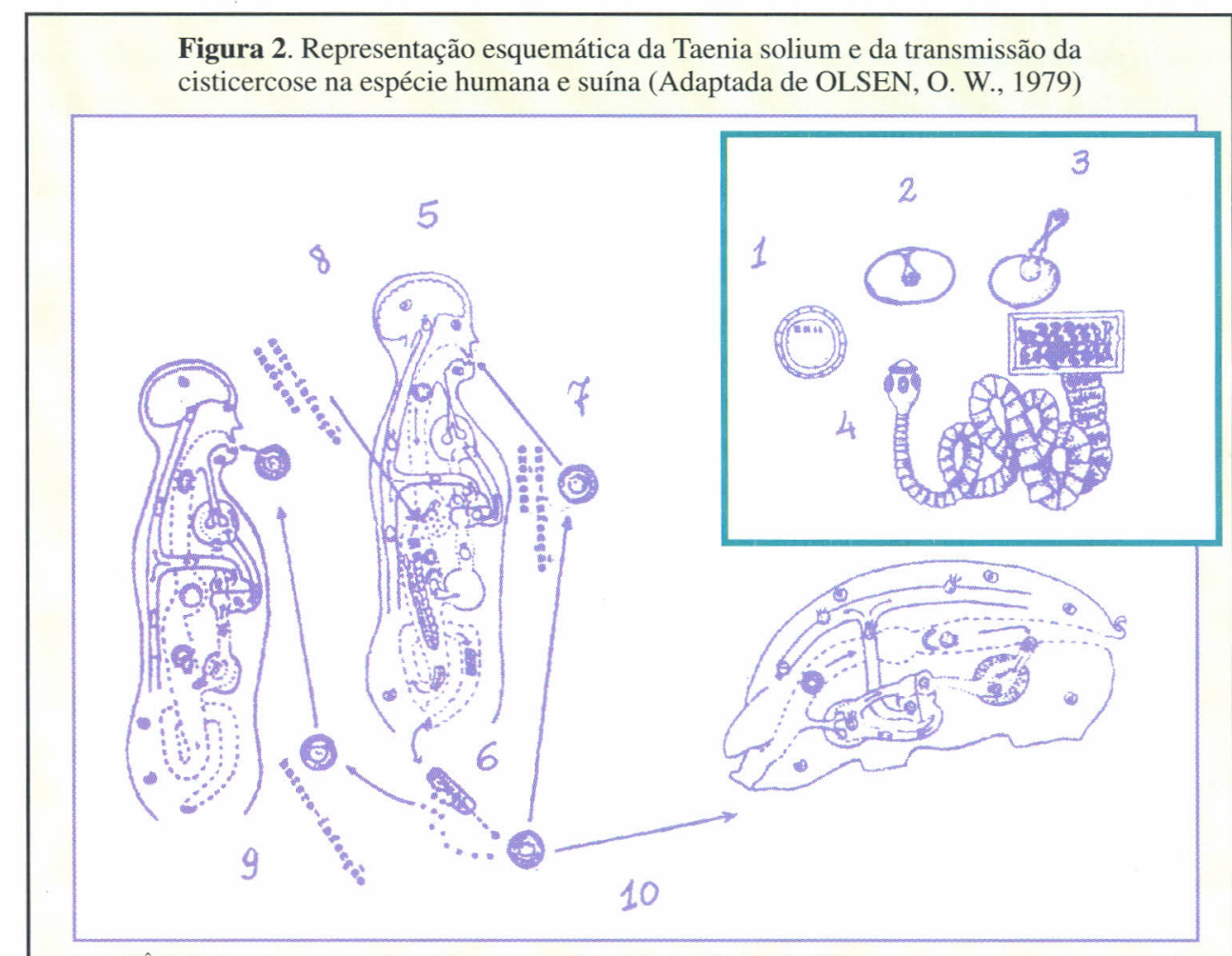

Fonte: CÔRTES, J. A. Comum. cient. Fac. Méd. vet. Zootec. Univ. S. Paulo. 8(2): 231-41, 1984.

1. Ovo da tênia com sua estrutura interna e envoltório externo; 2. Cisticerco invaginado; 3. Cisticerco desinvaginado; 4. Taenia solium (forma adulta); 5. Portador da tênia (Fonte de infecção); 6. Eliminação de proglotes e liberação dos ovos (Vias de eliminação); 7. Auto-infecção exógena; 8. Auto-infecção endógena; 9. Hetero-infecção (novo hospedeiro humano e fluxo da patogenia no ser humano); 10. Infecção do suíno e fluxo da patogenia no suíno. 
CÔRTES, J. A. Complexo teníase humana - Cisticercose bovina e suína - II Cisticercose bovina e suína / Human taeniasis - cattle and swine cysticercosis complex II Cattle and swine cysticercosis. Rev. educ. contin. CRMV-SP / Continuous Education Journal CRMV-SP, São Paulo, volume 3, fascículo 2, p. 61 - 71, 2000.

leva à boca e ingere ovos do parasita, eliminados com suas próprias fezes (ânus - mão - boca);

- Auto-infecção endógena: decorrente de um processo de retroperistaltismo quando, por um refluxo do conteúdo intestinal, ovos maduros da tênia, que ele próprio alberga, chegam ao estômago e retornam, posteriormente, ao intestino, sofrendo, assim, a ação dos sucos gástrico e entéricos, com conseqüente ativação do embrião e estabelecimento da infecção.

Em bovinos, a infecção pré-natal, pela forma larvar da Taenia saginata, ocorre raramente e, em suínos, não se tem registro de animais recém-nascidos infectados pela da Taenia solium (ABDUSSALAM, 1974).

\section{Patogenia}

A ingestão de ovos maduros é indispensável para que a infecção cisticercótica se instale (EUZEBY ,1966; ABDUSSALAM, 1974; ALUJA et al., 1987; CÔRTES, 1984; SCHENONE, 1989; REY, 1991; ACHA e SZYFRES, 1996), isto é, a cisticercose só ocorre, em condições naturais, quando um hospedeiro adequado ingere ovos maduros da Taenia solium e/ou de Taenia saginata. Ao atingir o estômago e intestino, a ação combinada do suco gástrico e da pepsina inicia um processo de digestão do embrióforo, que se completa com a intervenção da tripsina pancreática. Nesta fase ocorre a ativação do embrião hexacanto pela ação conjunta da bile, colesterol e tripsina.

Uma vez em liberdade, o embrião insinua-se através das estruturas anatômicas da mucosa intestinal, ganha a circulação sangüínea, sendo, então, transportado, passivamente, até a sede de sua localização definitiva, em diferentes órgãos e tecidos, especialmente aqueles que, como o tecido subcutâneo, músculos esquelético e cardíaco, sistema nervoso, globo ocular, etc. (ABDUSSALAM, 1974; CÔRTES, 1984; ALUJA et al., 1987; PATAK, 1989; SCHENONE, 1989; REY, 1991; ACHA e SZYFRES, 1996), apresentem uma intensa irrigação decorrente de uma maior atividade funcional.

De um modo geral, tanto em suínos como em bovinos, o miocárdio, a língua e o masseter, assim como os músculos do braço, o esôfago, o diafragma, os músculos intercostais, os músculos da coxa, os pulmões e o cérebro figuram como os tecidos mais freqüentemente parasitados.

Tal eletividade é, contudo, relativa, uma vez que cisticercos têm assumido localizações particulares como a câmara anterior do globo ocular e o tecido submucoso da língua e orifícios anal e vulvar, especialmente nas espécies suína e humana.
$\mathrm{Na}$ verdade, muito pouco se conhece a respeito da migração do embrião das tênias, desde a porta de entrada, ao nível do inteștino, até sua localização final, nos tecidos de eleição do hospedeiro (ALUJA et al., 1987).

$\mathrm{Na}$ fase de invasão os embriões podem provocar um processo de enterite catarral aguda com presença de pontos hemorrágicos na mucosa intestinal. Mecanismo semelhante explica as hemorragias lineares do parênquima hepático e conseqüentes peritonite e hepatite traumáticas, que surgem, particularmente, nos casos de parasitismo intenso pelo Cysticercus cellulosae. Registre-se, ainda, que, em sua passagem pelo fígado e pulmões, podem localizar-se nestes órgãos, originando lesões hepáticas e pulmonares importantes. Ao atingirem a grande circulação tem início a fase de disseminação que resulta na dispersão, fixação e desenvolvimento da larva nos diferentes sítios preferenciais do parasita.

Chegando a seu destino, os embriões abandonam os capilares da circulação e assestam-se no tecido conectivo que circunda as fibras musculares, onde evoluirão até completar sua forma vesicular, o cisticerco. A oncosfera sofre um processo de vesiculização, perde seus seis acúleos e diferencia-se internamente dando origem a um escolex invaginado, consoante a espécie da tênia. À medida que se desenvolve, exerce uma ação mecânica desviando as fibras musculares de seu curso normal, e uma ação bioquímica, provocando a lise do tecido perilarvar, sob o efeito de enzimas proteolíticas de origem parasitária, desencadeando uma reação inflamatória subaguda com aspecto de um granuloma cístico, caracterizado por uma reação epitelióide, com células gigantes e eosinófilos, enquanto a periferia é circunscrita por uma cápsula de fibras conjuntivas. Finalmente, os cisticercos exercem uma ação antigênica, estimulando o organismo do hospedeiro a elaborar anticorpos. Tal ação só se verifica na fase inicial da infecção, antes que a cápsula fibrosa isole o parasita.

Os primeiros estágios, visíveis macroscopicamente, podem ser detectados, nos músculos, por volta de 6 a 12 dias após a infecção, sob a forma de lesões esbranquiçadas de aspecto globuloso, com um diâmetro de 1 a 2 milímetros. Ditas lesões alcançam sua estrutura vesicular característica em aproximadamente 6 semanas (40 dias), todavia o cisticerco somente estará completamente maduro após 60 a 75 dias da infecção (ALUJA et al., 1987; PATAK, 1989; REY, 1991).

Embora o processo de evolução dos cisticercos, tanto da Taenia solium como da Taenia saginata, seja fundamentalmente o mesmo, estruturalmente estas vesí- 
CÔRTES, J. A. Complexo teníase humana - Cisticercose bovina e suína - II Cisticercose bovina e suína / Human taeniasis - cattle and swine cysticercosis complex II Cattle and swine cysticercosis. Rev. educ. contin. CRMV-SP / Continuous Education Journal CRMV-SP, São Paulo, volume 3, fascículo 2, p. 61 - 71, 2000.

culas apresentam algumas diferenças importantes. Enquanto o Cysticercus bovis apresenta um escolex inerme, com ventosas elípticas, e invaginado numa posição cefálica, o Cysticercus cellulosae apresenta quatro ventosas circulares protegidas por um rostelo armado com duas coroas de ganchos e está invaginado numa posição nitidamente equatorial em relação à vesícula (ALUJA et al., 1987).

Ainda que nos animais tais lesões vesiculares não acarretem, aparentemente, maiores transtornos ao organismo, nos seres humanos a forma larvar da Taenia solium pode assumir uma gravidade extrema na dependência da localização, do número e tamanho, bem como da fase de desenvolvimento dos cistos. No globo ocular, por exemplo, evolui para a opacificação dos meios e a desorganização intra-ocular, acarretando a perda da visão e do próprio globo ocular. Já no encéfalo, as alterações variam com a estrutura comprometida (ALUJA et al., 1987; REY, 1991). Após a morte os cisticercos sofrem, usualmente, degeneração caseosa e calcificação. Eventualmente, pode ocorrer a invasão do cisto por agentes piogênicos seguida de supuração com formação de um abscesso lenticular ou pisciforme, daí a cautela que deve nortear as terapêuticas antiparasitárias.

De particular importância epidemiológica é a longevidade dos cisticercos. Tal período de sobrevivência destes parece ser maior nos animais que contraem a infecção durante as primeiras semanas de vida (ABDUSSALAM, 1974; REY, 1991; ACHA e SZYFRES, 1996). Em bovinos, com o sistema imunológico completamente desenvolvido, o Cysticercus bovis não sobrevive mais que 9 meses após a infecção, ao passo que nas infecções ocorridas no período neonatal os tais cisticercos podem sobreviver por vários anos, ou mesmo por toda a vida do animal (REY, 1991; ACHA e SZYFRES, 1996). Nos suínos e humanos, entretanto, o Cysticercus cellulosae pode sobreviver por vários anos (ALUJA et al., 1987; ACHA e SZYFRES, 1996).

O estado de saúde do hospedeiro parece também influir decisivamente sobre a longevidade dos cisticercos. As doenças ictéricas, com impregnação muscular de sais e pigmentos biliares, aceleram a morte do parasita. Do mesmo modo a tuberculose acelera o processo de calcificação.

O tecido de localização é outra variável a ser considerada. Nos pulmões, coração e fígado, o cisto da Taenia saginata pode degenerar ao fim de 20 dias, ao passo que, no tecido muscular estriado, a maioria dos cistos degenera e calcifica-se de 9 a 12 meses após a infecção inicial e, alguns deles, podem continuar viáveis por longo tempo (ABDUSSALAM, 1974).

\section{Sintomas}

O período de incubação é muito variável podendo oscilar entre 15 dias e muitos anos após a infecção (ACHA e SZYFRES, 1996). Todos reconhecem que o quadro sintomatológico da cisticercose é, em geral, inaparente em todas as espécies hospedeiras, salvo quando os cistos se localizam em estruturas particulares, interferindo na atividade de órgãos vitais, ou quando a infecção é extremamente intensa.

Nos bovinos e suínos, a cisticercose raramente manifesta-se como doença clinicamente reconhecível. De fato, formas graves são extremamente raras em bovinos, todavia, casos de cardiopatia, com degeneração do miocárdio e morte súbita têm sido registrados. Já nos suínos episódios isolados de hiperestesia do focinho, paralisia da língua e convulsões epilépticas têm sido atribuídos à ação dos cisticercos. Nesses animais, durante a fase de invasão dos embriões, pode ocorrer um quadro de enterite ou enteroperitonite traduzido por diarréia, cólicas e tensão da parede abdominal, que pode ser dolorosa à palpação.

Durante a fase de disseminação, os sintomas, quando presentes, estão relacionados com a dispersão dos embriões nos diferentes tecidos e traduzem-se por: dificuldade na apreensão dos alimentos, na mastigação e, até mesmo, uma pseudoparalisia do maxilar inferior, nos casos de infecção maciça dos músculos mastigadores e da língua; tosse seca e quitinosa, nos ataques aos músculos ou à submucosa do laringe; transtornos locomotores e cerebrais, nos casos de infecções intensas.

Nos cães os cisticercos alojados no cérebro podem causar uma síndrome semelhante à raiva (ABDUSSALAM, 1974; ACHA e SZYFRES, 1996).

Na espécie humana, a cisticercose constitui sempre uma patologia de prognóstico reservado. Sua localização cerebral, por exemplo, é muito perigosa e pode ocasionar transtornos nervosos como: epilepsia; aumento da pressão intracraniana; meningite crônica, simulando lesões de meningite tuberculosa crônica; manifestações psiquiátricas; encefalite e radiculomielopatias, devidas ao envolvimento da medula espinhal e suas membranas (ABDUSSALAM, 1974; ALUJA et al., 1987; PATAK, 1989; SCHENONE, 1989; ADAMOLEKUN, 1995). São igualmente graves as consequiências da localização do cisto no globo ocular, nos músculos ou no coração (ABDUSSALAM, 1974; ALUJA et al., 1987; PATAK, 1989; SCHENONE, 1989). A morte do cisto provoca uma reação no tecido em que está alojado e os produtos resultantes da degeneração da larva podem passar a exercer uma ação tóxica e irritativa bem mais acentuada. 


\section{Diagnóstico}

É reconhecimento geral a impossibilidade do estabelecimento de um diagnóstico clínico definitivo da cisticercose, em qualquer espécie, em razão de ser o quadro sintomatológico por demais inespecífico.

Nos suínos, um sinal externo indicativo da doença, a localização sublingual, passível de ser descoberto por ocasião da inspeção dos animais, representa grande contribuição para o diagnóstico (ABDUSSALAM, 1974), todavia sua presença só é evidente em uma parcela pequena dos animais, de sorte que a descoberta dos portadores irá depender da associação dos recursos de vigilância epidemiológica disponíveis com os rebanhos de origem dos animais.

Na espécie humana, a significativa gravidade dos casos manifestos, quase sempre indissociáveis clinicamente das manifestações de numerosas outras patologias correlatas, torna imprescindível a utilização de numerosos procedimentos de natureza diferencial envolvendo o laboratório.

Em qualquer espécie, as informações obtidas por ocasião da anamnese ou as evidências epidemiológicas obtidas a partir dos registros sanitários, eventualmente disponíveis, podem oferecer subsídios valiosos no encaminhamento do diagnóstico dessa doença.

A presença de portadores de Taenia saginata entre o pessoal de uma granja de exploração de bovinos justifica a suspeita de cisticercose na criação; do mesmo modo que o histórico de pacientes humanos procedentes de áreas que praticam a exploração familiar de suínos, em condições promíscuas, com hábitos alimentares duvidosos e com história de teníase no passado ou presente, pode contribuir para a suspeita diagnóstica.

O diagnóstico anatomopatológico constitui-se, sem sombra de dúvida, no instrumento de maior importância em Medicina Veterinária, pois a identificação da cisticercose, por ocasião do abate dos animais, é indispensável ao sucesso dos programas de prevenção à teníase humana. Desde sua introdução, em Roma, atribuída a Galeno (130-200 d.C.) (CÔRTES, 1993), a Inspeção de Carnes, tanto bovina como suína, tem-se constituído no principal instrumento diagnóstico da cisticercose em animais e conseqüente prevenção da teníase. Por seu turno, a associação epidemiológica dos achados de matadouro com a procedência dos animais abatidos possibilita a descoberta, a custo reduzido, de áreas endêmicas deste complexo.

Contudo, a inspeção de carnes baseada em cortes preferenciais é, evidentemente, insuficiente como recur- so diagnóstico, exclusivo para a prevenção, uma vez que pode deixar de detectar parcela expressiva dos animais afetados (ABDUSSALAM, 1974; ACHA e SZYFRES, 1996), particularmente nos casos de infecção leve, condição muito freqüente na cisticercose bovina.

Evidentemente, o exame anatomopatológico (biópsia) de nódulos subcutâneos encontrados em pacientes humanos bem como o teste intradérmico (PATAK, 1989) podem propiciar elementos diagnósticos da maior relevância (ACHA e SZYFRES, 1996), notadamente em se tratando de decisão diferencial ante os quadros neurológicos (REY, 1991).

Entre os procedimentos do diagnóstico laboratorial, em humanos, figuram: o exame do líquido cefalorraquídeo (ALUJA et al., 1987; REY, 1991), incluindo os testes imunológicos de ELISA (ALUJA et al., 1987; BONAMETTI et al., 1992; PATAK, 1989; REY, 1991), imunoeletroforese (ALUJA et al., 1987; PATAK, 1989; REY, 1991), contra imunoeletroforese (PATAK, 1989), imunofluorescência indireta (ALUJA et al., 1987; REY, 1991), hemaglutinação indireta PATAK, 1989; REY, (1991), imunodifusão dupla (ALUJA et al., 1987; REY, 1991), ensaio imunoenzimático de eletrotransferência (EITB) (CRUZ et al., 1995), fixação de complemento (ALUJA et al., 1987; REY, 1991); e no diagnóstico por imagem figuram com destaque a tomografia computadorizada (ALUJA et al., 1987; CREASEY e ALARCON, 1994) e a ressonância magnética nuclear (CREASEY e ALARCON, 1994).

Para animais, em que pese a existência de um número crescente de testes sorológicos, com resultados experimentais animadores, reações inespecíficas podem ser desalentadoras nos casos de infecções naturais. Nesse sentido, as reações de ELISA baseadas em anticorpos monoclonais, que detectam antígenos circulantes, indicadores de presença de cisticercos vivos, parecem promissoras e podem revelar-se muito úteis na inspeção de carnes, tanto para detecção da cisticercose no animal vivo, como para exame sorológico em matadouro, desde que devidamente automatizadas para uso durante a rotina de inspeção (OIE, 1996).

\section{Tratamento}

O tratamento da cisticercose humana reveste-se de extrema cautela e tem sido conduzido segundo três procedimentos, consoante a orientação do diagnóstico estabelecido, a saber: o tratamento sintomático, o cirúrgico e o quimioterápico. 
Em alguns casos o processo cirúrgico descompressivo, com desvio do fluxo do líquido céfalorraquídeo e/ou extirpação do cisto, pode induzir a resultados animadores; em outras situações a adoção de uma conduta farmacológica orientada para o combate à sintomatologia pode resultar satisfatória. A terapêutica antiparasitária tem propiciado resultados animadores, sem, contudo, reverter os danos definitivos eventualmente já desenvolvidos no organismo do hospedeiro (ALUJA et al. 1987). Entre os produtos utilizados figuram com maior destaque o Praziquantel e, mais recentemente, o Albendazol (ALUJA et al. 1987; REY, 1991; TAKAYANAGUI, 1998). A despeito da relativa eficiência desses produtos na terapêutica etiológica da neurocisticercose, sua adoção deve cercar-se de cuidadosa análise médica, particularmente no tocante à viabilidade, à quantidade e à localização dos cistos, persistindo um certo grau de incerteza quanto ao benefício, à falibilidade e aos riscos desta terapêutica (TAKAYANAGUI, 1998). Os riscos aludidos incluem o fato de que a morte e degeneração dos cisticercos podem provocar uma reação inflamatória nos tecidos em que se encontram alojados, agravando o quadro clínico de uma cisticercose cerebral ou ocular.

Todos estes aspectos oferecem elementos para admitir-se ser a prevenção da infecção do hospedeiro humano a verdadeira solução para os problemas da neurocisticercose (TAKAYANAGUI, 1998).

Nos animais, a quimioesterilização dos cisticercos, se viabilizada economicamente, poderá ter um grande significado social não apenas como elemento de prevenção da teníase do homem (ABDUSSALAM, 1974), mas também como fator de produtividade dos rebanhos.

\section{Profilaxia}

A profilaxia da cisticercose fundamenta-se em duas linhas básicas de ação que buscam interromper a cadeia de transmissão da doença (ABDUSSALAM, 1974), a saber:

- medidas indiretas que visam impedir que o homem adquira teníase, já analisada no artigo anterior;

- medidas diretas, que têm por escopo proteger os hospedeiros suscetíveis contra a infecção decorrente da ingestão de ovos da tênia. Nesta última categoria incluem-se, particularmente, as seguintes possibilidades de atuação:

\section{Sobre as fontes de infecção}

a) Identificar os portadores de tênia (busca ativa dos portadores de teníase), por meio de:
- uma ação global de diagnóstico massal de toda a população humana, o que se configura como um procedimento extremamente oneroso e de difícil operacionalidade, praticado na Rússia como parte de um amplo programa de erradicação de várias zoonoses parasitárias (BESSONOV, 1974);

- um procedimento estratégico integrado, envolvendo os sistemas de saúde humana e animal, objetivando, inicialmente, a localização das propriedades de origem dos animais com cisticercose, e, num segundo passo, o exame diagnóstico de todo o pessoal do grupo de risco da correspondente área.

- controle sanitário dos manipuladores de alimentos, incluindo nos exames regulamentares de saúde, a pesquisa de portadores de teníase.

b) Tratamento dos indivíduos portadores de tênia. Para tanto, lançar mão dos tenicidas e tenífugos disponíveis. É recomendável que se recolha e esterilize as matérias fecais eliminadas nas 24 horas subseqüentes ao tratamento anti-helmíntico.

O tratamento precoce da teníase é fundamental para evitar uma eventual auto-infecção endógena dos portadores da Taenia solium.

\section{Sobre as vias de transmissão}

O saneamento ambiental, particularmente com vistas ao destino e tratamento adequado dos excretas humanos:

- nas regiões onde existe rede de esgotos é necessário garantir a esterilização parasitária das águas residuais antes que estas venham a ser lançadas nos cursos d'água ou nos campos de cultura ou criação;

- nos aglomerados onde estes não existem, bem como nas áreas de campanha, é necessário observar as regras estritas relativas ao adequado destino dos dejetos humanos, como:

- uso obrigatório de fossas;

- proibição do uso de dejeções humanas não tratadas adequadamente para a fertilização dos campos, notadamente dos efluentes dos "campings" ou de sanitários de veículos aéreos, terrestres ou de cabotagem.

\section{Sobre os suscetíveis}

- Adotar práticas de manejo, objetivando a qualidade sanitária dos rebanhos, como as granjas de suínos tecnificadas; 
- evitar a promiscuidade no convívio entre pessoas e animais, particularmente, nos confinamentos de bovinos;

- adotar medidas de higiene pessoal, visando evitar a infecção por contatos pessoais com mãos sujas do próprio portador ou de terceiros;

- adotar medidas de higiene alimentar, objetivando evitar a ingestão de ovos de Taenia solium com os ali- mentos, particularmente no caso de verduras cruas, lavadas inadequadamente, ou de água de procedência duvidosa.

\section{Sobre a comunidade}

Orientação sanitária da comunidade acerca dos procedimentos acima apontados.

\section{SUMMARY}

Cysticercosis has been included among the most important known zoonosis, not only because it causes damages to animals' health and consequent economic losses but also due to the severity of the disease in the human population. It is caused by the larval stage (metacestodes) of Taenia solium and Taenia saginata. Based on the interactive relationship existing among the adult and larval stages of these parasites and their hosts, this papper reviews the natural history and prevention of the disease. The subject is approached so as to include the taeniasis-cysticercosis complex transmission mechanisms both from animals to man (taeniasis), as presented in a previous article, and from man to animals (cysticercosis). Several aspects are emphasized: a) the role of cysticercosis carriers on the transmission of human taeniasis; b) the meaning of the silent course of the disease and of the nonspecific clinical manifestations; c) the importance of an epidemiological surveillance system to identify the risk groups and to establish preventive interventions; d) the direct preventive actions. These preventive actions are based on 1) the diagnosis and treatment of taeniasis carriers, as supported by veterinary inspection detecting cysticercosis in the slaughter house, associating the cases with the of the affected animals herds and notification to health authorities; 2) environment sanitation related to adequate disposal and treatment of human faeces; 3 ) non-specific protection of susceptible individuals by sanitary management practices in animal populations and personal and food hygiene in human populations; 4) involvement of the communities in relation to individual procedures and prevention practices.

Key words: taeniasis-cysticercosis complex, animal cysticercosis, human taeniasis, Cysticercus cellulosae, and Cysticercus bovis.

\section{REFERÊNCIAS BIBLIOGRÁFICAS}

1 - ABDUSSALAM, M. El problema de la teniasis-cisticercosis. Washington: Organización Panamericana de la Salud, 1975. (Publicación científica, 295). Reunión Interamericana.

2 - ACHA, P. N.; SZYFRES, B. Zoonosis y enfermedades transmisibles comunes al hombre y a los animales. 2. ed. Washington: Organización Panamericana de la Salud, 1996. (Publicación científica, n. 505).

3 - ADAMOLEKUN, B. The aetiologies of epilepsy in tropical Africa. Tropical and Geographical Medicine., v. 47, n. 3, p. 115-7, 1995.
4 - ALUJA, A S.; ESCOBEDO, A.E.F.; LACLETTE, A.F.J.P.; MADRAZO, C.L.I.; WILLMS, V.V.K. Cisticercosis. Biblioteca de la Salud. Instituto Nacional de Salud Publica; Mexico, 1987, p.115.

5 - BESSONOV, A S. Perspectives on the eradication of several helminthozoonotic diseases in the URSS. In: SOULSBY, E.J.L. Parasitic zoonoses. Clinical and experimental studies. New York: Academic Press, 1974. p. 179-86.

6 - BONAMETTI, A.M.; BASILE, M.A.; VAZ, A.J.; BALDY, J.L.S.; TAKIGUTI, C.K. Positivity enzyme-linked immu- 
nosorbent assay (ELISA) rates for cysticercosis in the cerebrospinal fluid (CFS) and in the serum of patients with epilepsy. Revista do Instituto de Medicina Tropical de São Paulo.v. 34, n. 5, p. 451-8. 1992.

7 - CÔRTES, J. A. Epidemiologia do processo teníase humana cisticercose. Comunicações Científicas da Faculdade de Medicina Veterinária e Zootecnia da Universidade de São Paulo, v. 8, n. 2, p. 231-41, 1984.

8 - CÔRTES, J. A. Epidemiologia. Conceitos e princípios fundamentais. São Paulo: Livraria Varella, 1993. p. 227

9 - CREASEY, J.L.; ALARCON, J.J. Magnetic resonance imaging of neurocysticercosis. Topics in Magnetic Resonance Imaging. v. 6, n. 1, p. 59-68, 1994.

10 - CRUZ, M.E.; CRUZ, I.; PREUX, P.M.; SCHANTZ, P.; DUMAS, M. Headache and cysticercosis in Ecuador, South America. Headache, v. 35, n. 2, p. 93-7, 1995.

11 - EHNERT, K.L.; ROBERTO, R.R.; BARRETT, L.; SORVILLO, F.J.; RUTHERFORD, G.W.III Cysticercosis: first 12 months or reporting in California. Bulletin of the Pan American Health Organization, v. 26, n. 2, p.165-72, 1992.

12 - EUZEBY, J. Les maladies vermineuses des animaux domestiques et leurs incidences sur la pathologie humaine. Paris: Vigot Frères, 1966.

13 - FUKUDA, R. T.; SANTOS, I. F; ANDRADE, C. R. Estudo comparativo entre técnicas de inspeção do diafragma para diagnóstico da cisticercose bovina. Higiene Alimentar. V. 12 , n. 55 , p. 51-62, 1998.

14 - GUEERTS, S. The taeniasis-cysticercosis complex in Africa. Bulletin des Séances - Academie des Sciences d'Outre Mer. v. 38, n. 2, p. 245-64. 1992.

15 - LETTAU, L.A.; GARDNER, S.; TENNIS, J. et al. Locally acquired neurocysticercosis-North Carolina, Massachusetts, and South Carolina, 1989-1991. Morbidity and Mortality. Weekly Report, v. 41, n. 1, p. 1-4, 1992.

16 - MOORE, A.C.; LUTWICK, L.I.; SCHANTZ, P.M. et al. Seroprevalence of cysticercosis in an Orthodox Jewish community. American Journal of Tropical Medicine and Hygiene, v. 53, n. 5, p. 439-42, 1995.

17- OFFICE INTERNATIONAL DES EPIZOOTIES. Manual of standards for diagnostic tests and vaccines. 3. ed. Paris: OIE, 1996. p. 723.

18 - PATAK, K.M.L. Cysticercosis in India. A review and update of cysticercosis caused by Taenia solium. Zoonosis Revista Internacional, Brasília, v. 1, n. 2, p. 21-9, 1989.
19 - PAWLOVSKY, Z.; SCHULTZ, M. G. Taeniasis and Cysticercosis (Taenia saginata). Advances in Parasitology. n. 10, p. 269-343, 1972.

20 - REY, L. Parasitologia. Parasitos e doenças parasitárias do homem nas Américas e na África. Rio de Janeiro: Guanabara Koogan, 1991.

21 - SARTI, G.E.; SCHANTZ, P.M.; AGUILERA, J.; LOPEZ, A. Epidemiologic observations on porcine cysticercosis in a rural community of Michoacan State, Mexico. Veterinary Parasitology, v. 41, n. 3/4, p. 195-201, 1992.

22 - SCHANTZ, P.M.; SARTI, E.; PLANCARTE, A.; WILSON, M.; CRIALES, J.L.; ROBERTS, J.; FLISSER, A. Community-based epidemiological investigations of cysticercosis due to Taenia solium: comparison of serological screening tests and clinical findings in two populations in Mexico. Clinical Infectious Diseases, v. 18, n. 6, p. 879-85, 1994.

23 - SCHANTZ, P.M.; KRAMER, M.H.J. Larval cestode infections: cysticercosis and echinococosis. Current Opinion in Infectious Diseases, v. 8, n. 5, p. 342-50, 1995.

24 - SCHENONE, H. La cisticercosis como problema de salud humana y animal. Washington: Organización Panamericana de la Salud, 1975. (Publicación científica, n. 295).

25 - TAKAYANAGUI, O. M. Complexo teníase/cisticercose. Revista do Conselho Federal de Medicina Veterinária, v. 4, n. 14, p. 9-12, 1998.

26 - VAZ, A. J.; HANASHIRO, A.S.G.; CHIEFFI, P.P.; FERREIRA, AW. Freqüência de indivíduos com anticorpos séricos anti-Cysticerccus cellulosae em cinco municípios do estado de São Paulo. Revista da Sociedade Brasileira de Medicina Tropical, v. 23, n. 2, p. 97-9, 1990.

27 - VESTER, A. The Golden Hamster as a definitive host of Taenia solium and Taenia saginata. Onderstepoort Journal Veterinary Research. v. 41, p. 23-8, 1974.

28 - VILLA, M.F.G. Situação Epidemiológica do Complexo Teníase/ cisticercose como Problema de Saúde Pública no Brasil. Higiene Alimentar, v. 9, n. 36, p. 8-11, 1995.

29. WHO CYSTICERCUS WORK GROUP IN PERU. The marketing of cysticercotic pigs in the Sierra of Peru. Bulletin of the World Health Organization, v. 71, n. 2, p. 223-28, 1993. 